\title{
Jak3 is involved in CCR7-dependent migration and invasion in metastatic squamous cell carcinoma of the head and neck
}

\author{
ZHONGTI ZHANG ${ }^{1}$, FAYU LIU ${ }^{2},{\text { ZHENNING } \text { LI }^{2}, \text { DAN WANG }}^{1}$, RUIWU LI $^{2 *}$ and CHANGFU SUN ${ }^{2 *}$ \\ Departments of ${ }^{1}$ Prosthodontics and ${ }^{2}$ Oral and Maxillofacial Surgery, School of Stomatology, \\ China Medical University, Shenyang, Liaoning 110002, P.R. China
}

Received July 30, 2015; Accepted January 6, 2017

DOI: $10.3892 / \mathrm{ol} .2017 .5861$

\begin{abstract}
Patients with cervical lymph node metastasis in squamous cell carcinoma of the head and neck (SCCHN) exhibit a poor prognosis and low 5-year survival rate. It has been proven that chemokine receptor 7 (CCR7) promotes cellular migration and invasion in metastatic SCCHN. In the present study, the metastatic SCCHN PCI-37B cell line was utilized to explore the role of Janus activated kinase-3 (Jak3) in the CCR7-mediated signaling pathway in metastatic SCCHN cells. It was observed that phospho-Jak3 was expressed in SCCHN tissues. In addition, when the PCI-37B cells were analyzed in response to chemokine ligand 19 (CCL19), the ligand of CCR7, at the indicated time points, the results of the present study demonstrated that CCR7 induced Jak3 activation, and inhibition of Jak3 activity using a specific inhibitor, ZM39923, significantly attenuated CCR7-induced Jak3 phosphorylation. Migration and invasion assays and immunofluorescence staining experiments demonstrated that CCL19 promoted cell migration, invasion and $\mathrm{F}$-actin rearrangment in CCR7-expressing SCCHN cells partially due to the activation of the Jak3 signaling pathway. These results demonstrate that the Jak3 signaling pathway is important for the CCR7-induced malignant biological behavior of SCCHN cells.
\end{abstract}

Correspondence to: Dr Ruiwu Li or Dr Changfu Sun, Department of Oral and Maxillofacial Surgery, School of Stomatology, China Medical University, 117 Nanjing Bei Jie, Heping, Shenyang, Liaoning 110002, P.R. China

E-mail: liruiwu88@163.com

E-mail: changfusun@hotmail.com

*Contributed equally

Abbreviations: SCCHN, squamous cell carcinoma of the head and neck; Jak3, Janus activated kinase-3; CCR7, chemokine receptor 7

Key words: chemokine receptor 7, squamous cell carcinoma of the head and neck, Janus activated kinase-3

\section{Introduction}

Squamous cell carcinoma of the head and neck (SCCHN) is a common and highly malignant tumor, typically identified in the middle or late stages of the disease, with a 5-year survival rate of $30 \%$ (1). SCCHN accounts for $>90 \%$ of all head and neck tumors (2). Regional cervical metastasis is one of the most significant biological behaviors of SCCHN. The extent to which the lymph nodes of various regions are involved and the sites of the cervical lymph node metastases are associated with poor patient prognosis $(3,4)$. Demonstrating the molecular mechanism of the development of cervical metastasis is necessary in providing novel strategies of SCCHN therapy.

It is known that chemokines and chemokine receptors participate in the development of metastasis in various types of cancer tissue $(5,6)$. Among these chemokine receptors, it has been observed that chemokine receptor 7 (CCR7) is highly expressed in metastatic lymph nodes and invasive SCCHN cells, promoting preferential lymph node metastasis (7). The interactions between CCR7 and its ligands serve a major role in the malignant metastasis process of head and neck tumors, and the upregulation of CCR7 significantly increases the migratory and invasive ability of SCCHN cells (8). Therefore, characterizing the specific role of the CCR7 signaling pathway in the malignant metastasis of SCCHN may be helpful to evaluate whether CCR7 acts as a novel target in SCCHN therapeutic strategies.

As a non-receptor protein tyrosine kinase, Janus kinase (Jak) has been demonstrated to serve an important role in regulating various cell signaling pathways. It was reported that the tyrosine phosphorylation of the members of the Janus family of kinases, including Jak1, Jak2, Jak3 and tyrosine kinase 2 (Tyk2), may be involved in the occurrence and development of prostate and breast cancer (9). Specifically, it has been demonstrated that Jak3 is involved in dendritic cell maturation and migration via the CCR7-mediated signaling pathway $(10,11)$. However, whether Jak3 was able to be tyrosine phosphorylated upon stimulation with chemokine ligand 19 (CCL19) in SCCHN cells, and the specific role of Jak3 activation in the migration and invasion of SCCHN cells, remains unknown.

In the present study, the role of Jak3 in SCCHN migration and invasion was evaluated. The appropriate dose and duration of CCL19 (a CCR7 ligand) treatment to activate 
Jak3 phosphorylation through the CCR7 signaling pathway was investigated. Furthermore, diverse methodologies were applied to examine the role of Jak3 activation on the biological behavior of SCCHN cells, including invasion and migration. In addition, the association between the expression of phospho-Jak3, lymphatic metastasis and clinical stage was investigated. The present study observed that the activation of Jak3, through the interaction of chemokine receptor CCR7 and its ligand, is significantly involved in the invasion and migration of metastatic SCCHN. These results demonstrate the role of CCR7 signaling in metastatic SCCHN and provide new therapeutic targets for SCCHN.

\section{Materials and methods}

Human tumor samples and cell lines. In total, 70 SCCHN specimens with the adjacent metastatic (or normal) lymph nodes and 10 normal human oral mucosal tissue were obtained from the Head and Neck Tumor Center, School of Stomatology, China Medical University (Shenyang, China). SCCHN classification, including primary tumors ( $\mathrm{T}$ ), regional lymph nodes $(\mathrm{N})$, distant metastasis $(\mathrm{M})$ and clinical stage, was determined according to the rules of the International Union Against Cancer for Head and Neck Cancer (Tumor node metastasis, TNM classification, 1997) (12). All procedures were performed in accordance with the provisions of the Declaration of Helsinki and approved by the Ethics Committee of the China Medical University. All the specimens were obtained with the consent of the patients prior to surgery and in accordance with Health Insurance Portability. Written informed consent was received from all individuals.

PCI-37B, a metastatic SCCHN cell line expressing CCR7, was donated by the University of Pittsburgh Cancer Institute (Pittsburgh, PA, USA). The cells were cultured in Dulbecco's modified Eagle's medium (DMEM) containing $10 \%$ fetal bovine serum, penicillin, and streptomycin in an atmosphere of $5 \% \mathrm{CO}_{2}$ and $95 \%$ air at $37^{\circ} \mathrm{C}$. The $\mathrm{ZM} 39923$ inhibitor treatment at the dose used did not affect the viability as determined using the Cell Counting Kit-8 (CCK8; cat. no. C0038; Beyotime Institute of Biotechnology, Haimen, China) according to the manufacturer's protocol.

Reagents and antibodies. CCL19 and monoclonal anti-human CCR7 antibody (10 $\mu \mathrm{g} / \mathrm{ml}$; cat. no. MAB197) were purchased from R\&D Systems (Minneapolis, MN, USA). The Jak3 inhibitor (ZM39923) and tetramethylrhodamine-labeled phalloidin were purchased from Santa Cruz Biotechnology, Inc. (Santa Cruz, CA, USA). Anti-Jak3 (cat. no. bs-2808R) and anti-phospho-Jak3 (Tyr785; cat. no. bs-3207R) were purchased from Beijing Biosynthesis Biotechnology Co., Ltd (Beijing, China).

Immunohistochemical analysis. All the tumoral and normal specimens were obtained for histology and immunohistochemistry assay according to the common protocol (13). Sections of $5 \mu \mathrm{m}$ thickness were deparaffinized in xylene for $10 \mathrm{~min}$, and subsequently rehydrated through a graded series of ethanol $(100,95$ and $70 \%)$ at room temperature. The sections were immersed in $100 \%$ methanol containing $0.3 \% \mathrm{H}_{2} \mathrm{O}_{2}$ to inhibit endogenous peroxidase activity for
$30 \mathrm{~min}$ at room temperature. For antigen retrieval, sections were put in a jar filled with $10 \mathrm{mM}$ sodium citrate buffer and heated for $10 \mathrm{~min}$ at $95^{\circ} \mathrm{C}$ using a microwave oven, and subsequently cooled to room temperature. Subsequently, sections were blocked via incubation with normal goat serum (cat. no. KIT-9706, Fuzhou Maixin Biotech Co., Ltd., Fuzhou, China) for $10 \mathrm{~min}$ at room temperature and incubated with rabbit polyclonal anti-phospho-Jak3 antibody (dilution, 1:100) overnight at $4^{\circ} \mathrm{C}$. The sections were washed and then incubated with $50 \mu 1$ undiluted biotinylated labeled secondary antibody (cat. no. KIT-9706, Fuzhou Maixin Biotech Co., Ltd.) for $1 \mathrm{~h}$ at room temperature, subsequent to the incubation of primary antibody. Then, following washing three times with PBS, sections were further incubated with a complex of avidin/streptavidin-peroxidase for $10 \mathrm{~min}$ at room temperature. Following diaminobenzidine development, the sections were then counterstained with hematoxylin for histology. Negative controls were conducted by exchange of primary antibody for PBS. Images were captured of the stained slides and they were analyzed by microscopy (Nikon Eclipse 80i; Nikon Corporation, Tokyo, Japan) at a magnification of x 100 . Tumors were classified according to the percentage of positive cells: Negative $(-), \leq 10 \%$ or no staining; weakly positive $(+), 11-50 \%$; positive (++), $51-75 \%$; or strongly positive (+++), $>75 \%$. For each experimental condition, $\geq 5$ randomly selected fields were analyzed.

Western blot assay. To explore whether Jak3 is phosphorylated by CCL19, the protein expression of phospho-Jak3 and Jak3 was determined using western blot analysis. PCI-37B cells were exposed to CCL19 at a concentration of $200 \mathrm{ng} / \mathrm{ml}$ for $0,0.25,1,5,10,15$ and $30 \mathrm{~min}$. The cells were lysed with ice-cold RIPA lysis buffer (Beijing Dingguo Changsheng Biotechnology Co., Ltd., Beijing, China) and centrifuged at $13,400 \times \mathrm{g}$ at $4^{\circ} \mathrm{C}$, for $30 \mathrm{~min}$. Using a BCA Protein assay kit, the protein concentration of the supernatants was determined. The supernatant in the aliquots, which contained equal amounts of total protein $(20 \mu \mathrm{g})$ were denatured and electrophoresed by $10 \%$ SDS-PAGE. Separated proteins were transferred to nitrocellulose filters. The membrane was blocked for $1 \mathrm{~h}$ at room temperature with $5 \%$ non-fat dried milk and subsequently incubated with rabbit polyclonal anti-Jak3 and anti-phospho-Jak3 antibody (both dilutions, 1:500) at $4^{\circ} \mathrm{C}$ overnight. The primary antibodies were labeled for $1 \mathrm{~h}$ with a horseradish peroxidase-conjugated secondary antibody (Beijing Zhongshan Jinqiao Biotechnology Co., Ltd., Beijing, China). $\beta$-actin (dilution, 1:1,000; cat. no. bs-0061R; Beijing Biosynthesis Biotechnology Co., Ltd.) served as an internal control. Bands were visualized using enhanced chemiluminescence with the BeyoECL Plus kit (P0018, Beyotime Institute of Biotechnology), according to the manufacturer's protocol. Subsequent to the determination of the time point of Jak3 activation, the cells were treated with Jak3 inhibitor (ZM39923, $10 \mu \mathrm{M})$ for $24 \mathrm{~h}$ or monoclonal anti-human CCR7 antibody $(10 \mu \mathrm{g} / \mathrm{ml})$ was used as an effective CCR7 inhibitor for $4 \mathrm{~h}$ at $37^{\circ} \mathrm{C}$. Subsequent to the cells being administrated with CCL19 for $5 \mathrm{~min}$, the cells were harvested and subjected to western blot analysis, as described above, to determine Jak3 and Phospho-Jak3 protein expression. 
Wound healing assay. Wound-healing assays were performed to investigate the cellular migration ability by measuring cell movement into a scraped cell-free area. The study groups consisted of control cells, cells treated with CCL19 alone and cells pretreated with ZM39923 for $24 \mathrm{~h}$ followed by CCL19. Cells were grown in 24-well plates and a cell-free area was created using a pipette tip. Wounded monolayers were washed with serum-free DMEM (Hyclone; GE Healthcare Life Sciences; Logan, UT, USA). Wound closure was observed after $24 \mathrm{~h}$ and images were captured using a microscope (Nikon TE2000-S Eclipse; Nikon Corporation) at magnification, $x 100$. The result was calculated as the percentage of the remaining cell-free space in comparison with the initial wound space at $0 \mathrm{~h}$. The experiments were performed in triplicate and between 4 and 5 scratches/well were analyzed.

Transwell and Matrigel assay. Transwell filter insert chambers ( 24 chambers with $8 \mu \mathrm{m}$ pore size) were used to evaluate the biological behavior of PCI-37B cellular migration and invasion. The cell suspensions $\left(2 \times 10^{5}\right.$ cell/200 $\left.\mu \mathrm{l}\right)$ were added to the upper chamber. Aliquots of the corresponding reagents (anti-CCR7 antibody or ZM39923) were added to the wells. Subsequently, CCL19 (aliquots of $500 \mathrm{ng} / \mathrm{ml}$ ) was added to the lower chamber. The cells were subjected to $24 \mathrm{~h}$ of incubation at $37^{\circ} \mathrm{C}$, and then cells in the lower well were fixed with ice-cold methanol for $30 \mathrm{~min}$ at room temperature, then stained with $0.1 \%$ crystal violet. For the cellular invasion assay, the procedure was performed similarly as aforementioned, but the upper chamber was precoated with $500 \mathrm{ng} / \mu \mathrm{l}$ Matrigel solution (BD Biosciences, Franklin Lakes, NJ, USA). For each experimental condition, $\geq 5$ randomly selected fields were analyzed by microscopy (Nikon TE2000-S Eclipse; Nikon Corporation, Tokyo, Japan) at a magnification of x200.

Immunofluorescence staining. The present study examined morphological changes in the actin cytoskeleton of SCCHN cells, which is required for tumor cell metastasis. PCI-37B cells were cultured in 24-well plates treated with $10 \mu \mathrm{g} / \mathrm{ml} \mathrm{CCR7}$ antibody for $4 \mathrm{~h}$ or $10 \mu \mathrm{M} \mathrm{ZM} 39923$ for $24 \mathrm{~h}$ at $37^{\circ} \mathrm{C}$, followed by treatment with CCL19 (final concentration of $500 \mathrm{ng} / \mathrm{ml}$ ) for $30 \mathrm{~min}$ at $37^{\circ} \mathrm{C}$. Cells were fixed in $4 \%$ paraformaldehyde for $10 \mathrm{~min}$, permeabilized using $0.1 \%$ Triton $\mathrm{X}-100$ for $5 \mathrm{~min}$ at $37^{\circ} \mathrm{C}$, stained with rhodamine-labeled phalloidin and diluted to a final concentration of $10 \mu \mathrm{g} / \mathrm{ml}$ in PBS (containing $1 \%$ bovine serum albumin; R\&D Systems, Inc., Minneapolis, $\mathrm{MN}, \mathrm{USA}$ ) for $1 \mathrm{~h}$ at $37^{\circ} \mathrm{C}$. Subsequently, the samples were washed 3 times for $10 \mathrm{~min}$. F-actin distribution was evaluated by fluorescence microscopy at $495 \mathrm{~nm}$.

Statistical analysis. All experiments were replicated $\geq 3$ times. Data are expressed as the mean \pm standard deviation. Differences were evaluated using the Student $t$-test or $\chi^{2}$ test. $\mathrm{P}<0.05$ was considered to indicate a statistically significant difference. All statistical analyses were performed with SPSS version 13.0 (SPSS, Inc., Chicago, IL, USA).

\section{Results}

Phospho-Jak3 is significantly expressed in tumor tissues and metastatic lymph nodes. In SCCHN tumor tissues, metastatic lymph nodes, normal oral mucosal tissues, the expression of phospho-Jak3 was investigated by immunohistochemical staining. The immunohistochemistry results revealed that the number of stained cells, expressing phospho-Jak3, was low or absent in normal oral mucosal tissues. By contrast, the staining of phospho-Jak3 presented in the cell cytoplasm in tumor cells and metastatic lymph node cells (Fig. 1). Additionally, the present study demonstrated that phospho-Jak3 expression was significantly associated with cervical lymph node metastasis and SCCHN clinical stage $(\mathrm{P}<0.01$; Table I).

Jak3 phosphorylation induced by CCL19 in CCR7-expressing SCCHN cells. To investigate whether Jak3 is involved in SCCHN metastasis mediated by the interaction between CCR7 and its ligands, the expression of phosphorylated Jak3 protein was examined in the metastatic SCCHN cell line as determined by western blot assay. Firstly, the PCI-37B cells were pretreated with CCL19 for 0, 0.25, 1, 5, 10, 15 and $30 \mathrm{~min}$, respectively. The results demonstrated that the expression of phospho-Jak3 protein was significantly modulated by CCL19 administration in a time-dependent manner. As presented in Fig. 2A, the increased expression of phosphorylated Jak3 protein appeared at $1 \mathrm{~min}$, and the maximal expression was identified at $5 \mathrm{~min}$ subsequent to treating by CCL19, which indicated that Jak3 activation by CCL19 at an appropriate dose was transient and reversible in the metastatic SCCHN cell line. Additionally, the effect of CCR7 in regulating Jak3 activation treated by CCL19 in the PCI-37B cells was investigated. CCL19 induced a marked increased expression of phosphorylated Jak3 protein after 5 min administration (Fig. 2A). By contrast, the phosphorylation of the molecule was blocked by CCR7 antibody or ZM39923 compared with CCL19 alone (Fig. 2B). The action of CCL19 was counteracted when the CCR7 blocker was used, which suggested CCL19 application was associated with CCR7 activation. These findings strongly suggested that the CCL19/CCR7 mediated signaling induced phosphorylated activation of Jak3 in PCI-37B cells.

Jak3 activation promotes the migration and invasion of PCI-37B cells. To evaluate whether Jak3 phosphorylation has an effect on the biological behavior of SCCHN cells, the present study analyzed the migration and invasion capability of SCCHN cells by wound healing assay and the Transwell assay. To determine PCI-37B cell migration rate, the scratch-wound assay was performed. Cells were grown in 24-well plates in DMEM to confluence for $24 \mathrm{~h}$, following the introduction of a wound by scratching. The present study demonstrated that subsequent to $24 \mathrm{~h}$ cells gradually migrated into the wound space along the wound edge. Compared with the control group, wound closure was significantly promoted in the PCI-37B cells upon addition of CCL19 at the $24 \mathrm{~h}(\mathrm{P}<0.05$; Fig. 3A), which exhibits that CCL19 enhanced the migration of PCI-37B cells. A special inhibitor of Jak3, ZM39923 significantly blocked the CCL19 induced wound closure rate compared with CCL19 alone $(\mathrm{P}<0.05$; Fig. 3A). The wound-healing assay proved that Jak3 activates the ability of migration of SCCHN cells.

Furthermore, the migration and invasion assays validated that CCL19 significantly accelerated tumor progression by increasing the migration and invasion ability of the PCI-37B cells. Compared to CCL19 alone, PCI-37B cells pretreated 
Table I. Association between phospho-Jak3 expression and clinicopathological factors of SCCHN.

\begin{tabular}{|c|c|c|c|c|c|}
\hline \multirow{2}{*}{$\begin{array}{l}\text { Clinicopathological } \\
\text { characteristic }\end{array}$} & \multirow{2}{*}{$\begin{array}{l}\text { No. of } \\
\text { patients }\end{array}$} & \multicolumn{2}{|c|}{ Phospho-Jak3 expression } & \multirow[b]{2}{*}{$\chi^{2}$ test } & \multirow[b]{2}{*}{ P-value } \\
\hline & & Positive & Negative & & \\
\hline Age, years & & & & & $>0.05$ \\
\hline$\geq 60$ & 39 & 21 & 18 & 0.125 & \\
\hline$<60$ & 31 & 18 & 13 & & \\
\hline Tumor size & & & & & $>0.05$ \\
\hline $\mathrm{T} 1 / \mathrm{T} 2$ & 55 & 30 & 25 & 0.142 & \\
\hline $\mathrm{T} 3 / \mathrm{T} 4$ & 15 & 9 & 6 & & \\
\hline Clinical stage & & & & & $<0.01$ \\
\hline $\mathrm{I} / \mathrm{II}$ & 33 & 10 & 23 & $16.339^{\mathrm{a}}$ & \\
\hline III/IV & 37 & 29 & 8 & & \\
\hline Nodal metastasis & & & & & $<0.01$ \\
\hline No & 35 & 12 & 23 & $13.027^{\mathrm{a}}$ & \\
\hline Yes & 35 & 27 & 8 & & \\
\hline
\end{tabular}

${ }^{\mathrm{a}} \mathrm{P}<0.01$ the internal difference of phospho-Jak3 expression within clinicopathological characteristics. Jak3, Janus activated kinase-3.

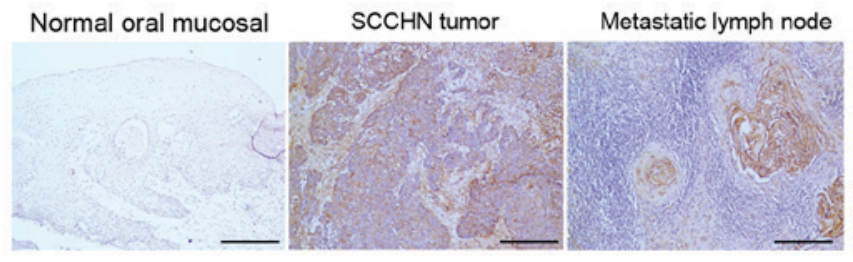

Figure 1. Expression of phospho-Jak3 was analyzed by immunohistochemistry. Representative stained images of normal oral mucosal tissues, SCCHN tissue and metastatic lymph nodes. Scale bars, $200 \mu \mathrm{m}$. Jak3, Janus activated kinase-3; SCCHN, squamous cell carcinoma of the head and neck.

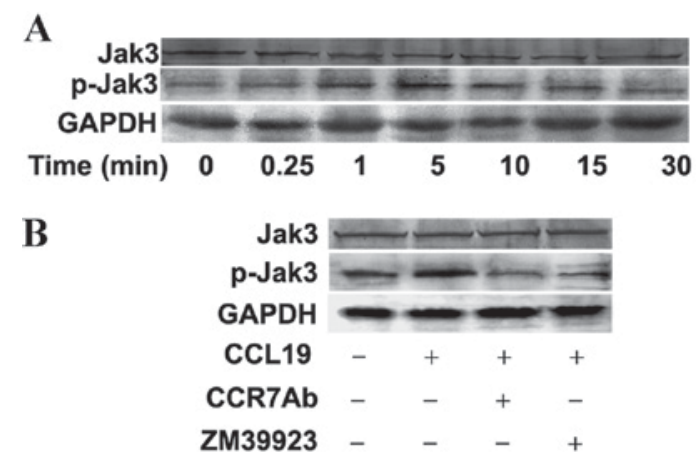

Figure 2. Jak3 phosphorylation induced by CCL19 in CCR7-expressing SCCHN cells was examined by western blot assay. (A) Time-course effect of CCL19 on Jak3 phosphorylation examined in PCI-37B cells. PCI-37B cells of control and CCL19 groups were treated with vehicle or $200 \mathrm{ng} / \mathrm{ml} \mathrm{CCL19}$ for $0,0.25,15,10,15$ and $30 \mathrm{~min}$, respectively. (B) Effect of CCR7 Ab and ZM39923 on CCL19-induced Jak3 activation in PCI-37B cells. PCI-37B cells pretreated with CCR7 Ab or ZM39923 followed by CCL19 were stimulated with $200 \mathrm{ng} / \mathrm{ml}$ CCL19 for $5 \mathrm{~min}$. Jak3, Janus activated kinase-3; CCL19, chemokine ligand 19; CCR7, chemokine receptor 7; SCCHN, squamous cell carcinoma of the head and neck; Ab, antibody.

with CCR7 antibody followed by CCL19 resulted a significantly decrease in migration and invasion ability $(\mathrm{P}<0.05$;
Fig. 3B). Similarly, ZM39923 followed by CCL19 also significantly decreased the migration and invasion of PCI-37B cells compared with CCL19 alone ( $<<0.05$; Fig. 3B). These results indicated that Jak3 performs an important role in the metastatic activity mediated through CCR7 in the metastatic SCCHN cell line.

Jak3 activation participates in $F$-actin rearrangement induced by CCL19 in CCR7-expressing SCCHN cells. F-actin, as the major component of cytoskeleton, performs a crucial role in tumor cell migration and motility. The rhodamine-labeled phalloidin staining demonstrated that there was a redistribution and intense impression of F-actin within the cells stimulated by CCL19. Evident pseudopodia formation was observed, which contributes to enhancing the migration and motility of PCI-37B cells. The reorganization of the F-actin was inhibited in the cells pretreated with CCR7 antibody or ZM39923, which indicated that Jak3 activation may be one of the mechanisms of F-actin polymerization induced by CCR7 and its ligands interaction (Fig. 4).

\section{Discussion}

The present experiments demonstrated that Jak3 is involved in modulating the migration and invasion induced by chemokine receptor CCR7 in metastatic SCCHN. The results of the present study may provide valuable insight into illustrating the complicated mechanisms of CCR7 signaling, through which tumor metastasis is promoted. The present study identified high expression of phospho-Jak3 in tumor tissues and metastatic lymph nodes. Phospho-Jak3 expression was associated with cervical lymph node metastasis and clinical stage of SCCHN. Additionally, the western blot analysis results demonstrated that Jak3 may be activated by CCR7 in PCI-37B cells. Furthermore, the wound healing and Transwell assays validated the hypothesis that Jak3 serves an important role 
A

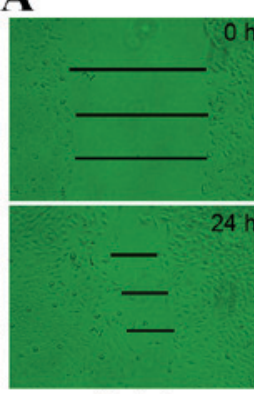

Control

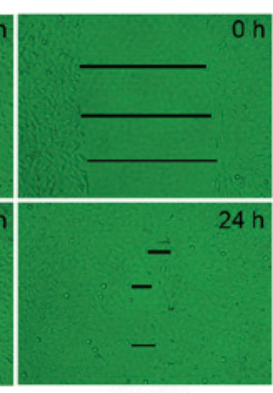

CCL19

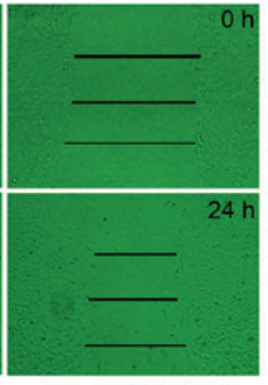

CCL19+ZM39923

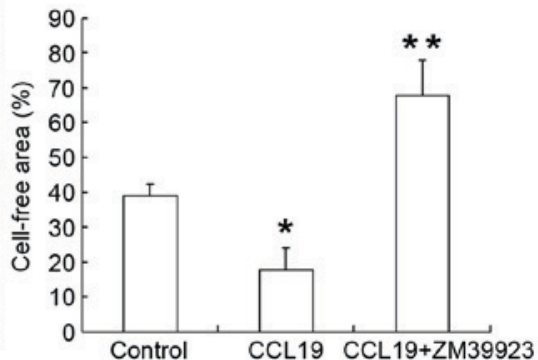

B
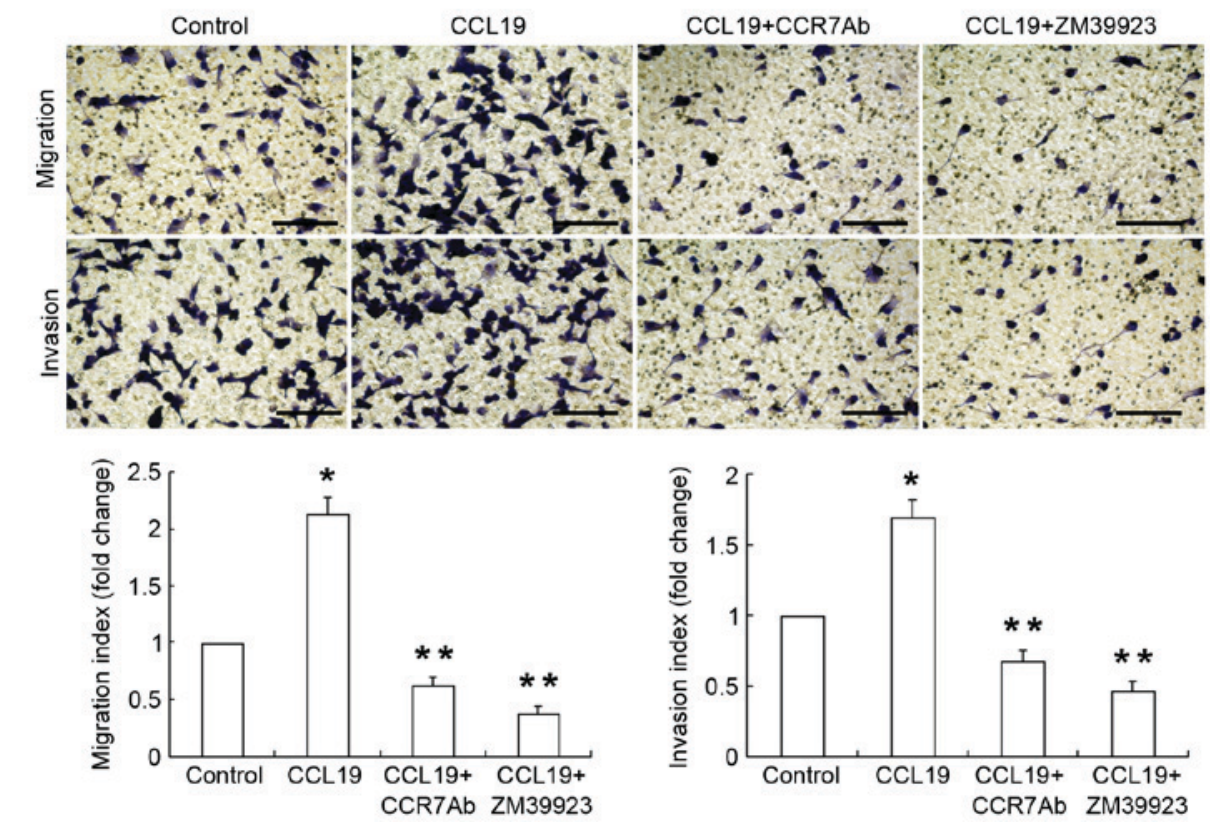

Figure 3. Jak3 activation enhances metastatic potential of SCCHN cells. (A) The cell migration rate was compared by wound healing assay. Wound closure was followed at 0 and $24 \mathrm{~h}$ subsequent to scratching the cell layer. (B) ZM39923 attenuated the cell migration and invasion induced by CCL19 application. Representative images and corresponding statistical data. Scale bars, $100 \mu \mathrm{m}$. Data are presented as the mean \pm standard deviation ( $\mathrm{n}=3$, each group). $\mathrm{P}<0.05$ vs. the control group, ${ }^{* *} \mathrm{P}<0.05$ vs. group of CCL19 alone. SCCHN, squamous cell carcinoma of the head and neck; CCL19, chemokine ligand 19; CCR7, chemokine receptor 7 .
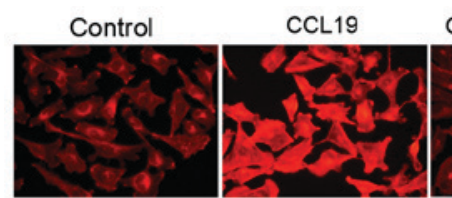

CCL $19+C C R 7 A b$

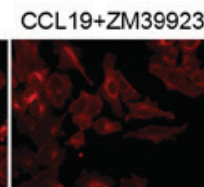

Figure 4. Jak3 inhibition blocks reorganization of the actin cytoskeleton induced by CCL19 in PCI-37B cells. The cells were stained with rhodamine-labeled phalloidin. Representative immunostaining images exhibiting control, CCL19 alone, CCR7 Ab followed by CCL19 and ZM39923 followed by CCL19 (original magnification, $\mathrm{x} 400$ ). Similar results were obtained from 3 independent experiments. Jak3, Janus activated kinase-3; CCL19, chemokine ligand 19; CCR7, chemokine receptor 7; Ab, antibody.

in CCR7-induced malignant biological behavior of SCCHN cells. Additionally, Jak3 inhibitor blocked F-actin rearrangement stimulated by CCL19 in CCR7-expressing SCCHN cells. Based on these results, the role of Jak3 was characterized in regulating the migration and invasion of SCCHN.

SCCHN, as a common malignant tumor of the head and neck, is characterized by a high degree of malignancy, high incidence of recurrence and metastasis, and high mortality. The combined treatment consisting of surgery or radiotherapy with postoperative adjuvant chemotherapy exhibits an improved outcome to prolong the overall survival in the treatment of SCCHN, but the prognosis remains far from optimistic due to the complexity and inscrutability of SCCHN $(14,15)$. Development of novel effective therapeutic strategies is urgent to improve life quality and reduce quantity of patients with recurrent or metastatic SCCHN. The low 5-year survival of SCCHN particularly depends on the regional nodal metastasis in the neck, and thus it is crucial to explore the associated mechanisms of cervical metastasis process of SCCHN to improve outcomes for these patients (16). Numerous clinical and experimental studies identified that chemokines and chemokine receptors have significantly affected the development, invasion and metastasis of a variety of tumors, apart from performing a role in the immune system. Presently, targeted-drug therapy is a promising adjuvant treatment approach in order to produce anti-tumor effects and result in an improved prognosis for the patient (17). Studies have suggested that chemokines and chemokine receptors act as potential therapeutic targets to 
inhibit tumor growth in malignant tumors (18). In particular, the CCL19/21-CCR7 signaling pathway has been associated with regional lymphatic nodal metastasis in a variety of tumors, including breast, gastric, and non-small cell lung cancer and melanoma $(19,20)$. CCR7, as a seven-transmembrane domain $\mathrm{G}$-protein-coupled receptor, presented a high expression in metastatic SCCHN and contributed to tumor progression and poor prognosis (21). Targeting of CCR7 and associated downstream molecules may control the migration and metastasis of SCCHN tumors (22). However, corresponding activation cascades of CCR7 pathway have not been accurately identified in detail in SCCHN.

The Jak family consists of 4 isoforms (Jak1, Jak2, Jak3 and Tyk2) and performs a pivotal role in the cytokine signaling pathway, modulating diverse cellular development, proliferation and differentiation (23). Among the Jaks, Jak3 that mainly exists in the lymphatic system and hematopoetic tissues, is a crucial tyrosine kinase in cell signal transduction for lymphocyte development and proliferation in the immune response (24). Jak3 is rapidly activated in phosphorylated form via cytokines by binding to their cell-surface receptors (25). Targeting Jak3-linked signal transduction pathways has shown effective immune suppression and anti-cancer effects $(26,27)$. The activation of the Jak3 pathway participates in the proliferation of certain types of cancer including cervical cancer (28). The selective Jak3 inhibitors have been proposed as potential therapeutic reagents targeting certain cytokine-associated diseases, unlike other Jak inhibitors possessing certain unintended side effects $(29,30)$. However, little is known regarding the role of the Jak3 signaling in SCCHN. To explore this problem, in the present study, the expression levels of Jak3 phosphorylation were detected at the indicated time points subsequent to the pretreatment of CCL19 at a dose of $200 \mathrm{ng} / \mathrm{ml}$ in a human SCCHN cell line, PCI-37B cultured in serum-free medium. The results of the western blot analysis revealed that CCL19 resulted in an increased phosphorylation of Jak3 in a time-dependent manner in PCI-37B cells. Additionally, immunohistochemical analysis demonstrated that there is an increased expression of phospho-Jak3 in tumor tissues and metastatic lymph nodes compared with the normal tissues. Additionally, the increased phospho-Jak3 expression was associated with condition of nodal metastasis and advanced stage, but not with age and tumor size $(\mathrm{P}>0.05)$. CCR7 was an independent risk factor for a higher nodal stage, recurrence and poor prognosis for SCCHN patients. Rivas-Caicedo et al (10) reported that Jak3 serves an important role in the cellular migration and function via the CCR7 pathway in the dendritic cell. The present study hypothesized that CCL19, by interacting with its receptor, CCR7, stimulated the activation of Jak3 in SCCHN. In the present study, PCI-37B cells were treated with or without Jak3 inhibitor ZM39923 or the CCR7 antibody followed by CCL19. The activation of Jak3 was inhibited by ZM39923 or the CCR7 antibody. As a result, the present study preliminarily proved that the interaction between CCR7 and its ligand, CCL19, enhanced Jak3 phosphorylation in the SCCHN cell line.

Previous studies have demonstrated that CCR7 expression is recognized as a key marker for predicting lymph nodal metastasis and tumor progression in tumor cells of breast and gastric cancer, as well as malignant melanoma (31-33). The authors previously investigated the role of CCR7 in tumor growth and metastasis in SCCHN $(34,35)$. Although it was shown that Jak3 is phosphorylated by the CCL19/CCR7 pathway in SCCHN tumor, additional descriptions of the role of Jak3 in SCCHN are required. To test whether Jak3 activation was involved in CCR7-mediated migration and invasion of SCCHN cell lines, the biological behavior in SCCHN was analyzed by inhibiting Jak3 signaling using specific inhibitor ZM39923. Cell mobility and migration was detected using a wound healing assay. The cellular migration rate was increased by CCL19 application at $24 \mathrm{~h}$ subsequent to scratching SCCHN cell layer, suggesting that migration may be increased by CCR7 activation $(13,35)$. These effects were blocked by the administration of ZM39923. Accordingly, the results of Transwell migration and invasion assays were consistent with the findings obtained by the wound healing assay. In addition, migration and invasion of cancer cells are functionally facilitated by actin cytoskeleton reorganization, and chemotherapeutic agents targeting the integrity of actin cytoskeleton were used to attenuate prostate cancer progression (36). In this study, an actin polymerization assay verified that ZM39923 also counteracted the effects of F-actin polymerization and pseudopodia formation as mediated by CCL19 in CCR7-expressing SCCHN cells. The alternations of cytoskeleton are the early events of migration, and are essential for the invasion and metastasis of tumor cells $(37,38)$. Therefore, all assays emphasized the importance of Jak3 activation in the migration and invasion of SCCHN cells mediated by CCR7 signaling, which revealed one of the mechanisms for the role of CCR7 in metastatic SCCHN. Additional studies investigating the response of molecules downstream of Jak3 induced by CCR7 in SCCHN tumor cells need to be performed in the future.

In conclusion, the present study highlights the growing importance of the Jak3 signaling pathway in the metastasis of malignant head and neck tumors mediated by the interactions of chemokine receptor CCR7 and its ligands. The results of the present study also contribute to the illustration of the complicated genetic regulation mechanism of CCR7 and provide a novel target for the treatment of SCCHN.

\section{Acknowledgements}

The present study was funded with the following grants: Science Public Welfare Research Fund Projects of Liaoning Province (grant nos., 2013001017 and 2011002001); Natural Science Foundation, China (grant nos., 81201800 and 81372877); and, Shenyang Science and Technology Plan Projects China (grant no., F12-277-1-68).

\section{References}

1. Greenlee RT, Hill-Harmon MB, Murray T and Thun M: Cancer Statistics, 2001. CA Cancer J Clin 51: 15-36, 2001.

2. Cognetti DM, Weber RS and Lai SY: Head and neck cancer: An evolving treatment paradigm. Cancer 113 (7 Suppl): S1911-S1932, 2008.

3. Inglehart RC, Scanlon CS and D'Silva NJ: Reviewing and reconsidering invasion assays in head and neck cancer. Oral Oncol 50: $1137-1143,2014$ 
4. Kiyota N, Tahara M and Fujii M: Adjuvant treatment for post-operative head and neck squamous cell carcinoma. Jpn J Clin Oncol 45: 2-6, 2015.

5. Sarvaiya PJ, Guo D, Ulasov I, Gabikian P and Lesniak MS: Chemokines in tumor progression and metastasis. Oncotarget 4: 2171-2185, 2013.

6. Ruffini PA, Morandi P, Cabioglu N, Altundag K and Cristofanilli M: Manipulating the chemokine-chemokine receptor network to treat cancer. Cancer 109: 2392-2404, 2007.

7. Wang J, Xi L, Hunt JL, Gooding W, Whiteside TL, Chen Z, Godfrey TE and Ferris RL: Expression pattern of chemokine receptor 6 (CCR6) and CCR7 in squamous cell carcinoma of the head and neck identifies a novel metastatic phenotype. Cancer Res 64: 1861-1866, 2004.

8. Wang J, Seethala RR, Zhang Q, Gooding W, van Waes C, Hasegawa $\mathrm{H}$ and Ferris RL: Autocrine and paracrine chemokine receptor 7 activation in head and neck cancer: Implications for therapy. J Natl Cancer Inst 100: 502-512, 2008.

9. Babon JJ, Lucet IS, Murphy JM, Nicola NA and Varghese LN The molecular regulation of Janus kinase (JAK) activation. Biochem J 462: 1-13, 2014

10. Rivas-Caicedo A, Soldevila G, Fortoul TI, Castell-Rodríguez A, Flores-Romo L and García-Zepeda EA: Jak3 is involved in dendritic cell maturation and CCR7-dependent migration. PLoS One 4: e7066, 2009.

11. García-Zepeda EA, Licona-Limón I, Jiménez-Sólomon MF and Soldevila G: Janus kinase 3-deficient T lymphocytes have an intrinsic defect in CCR7-mediated homing to peripheral lymphoid organs. Immunology 122: 247-260, 2007.

12. Loh KC, Greenspan FS, Gee L, Miller TR and Yeo PP: Pathological tumor-node-metastasis (pTNM) staging for papillary and follicular thyroid carcinomas: A retrospective analysis of 700 patients. J Clin Endocrinol Metab 82: 3553-3562, 1997.

13. Liu FY, Safdar J, Li ZN, Fang QG, Zhang X, Xu ZF and Sun CF: CCR7 regulates cell migration and invasion through MAPKs in metastatic squamous cell carcinoma of head and neck. Int J Oncol 45: 2502-2510, 2014.

14. Winquist E, Al-Rasheedy I, Nichols AC, Palma DA and Stitt L: Temporal changes in the efficacy of chemotherapy for recurrent or metastatic squamous cell carcinoma of the head and neck: A systematic review and meta-analysis. Cancer Treat Rev 40: 1073-1079, 2014

15. Nelke KH, Pawlak W, Gerber H and Leszczyszyn J: Head and Neck Cancer Patients' Quality of Life. Adv Clin Exp Med 23: 1019-1027, 2014

16. Noorlag R, van Kempen PM, Stegeman I, Koole R, van Es RJ and Willems SM: The diagnostic value of $11 \mathrm{q} 13$ amplification and protein expression in the detection of nodal metastasis from oral squamous cell carcinoma: A systematic review and meta-analysis. Virchows Arch 466: 363-373, 2015

17. Lee HJ, Song IC, Yun HJ, Jo DY and Kim S: CXC chemokines and chemokine receptors in gastric cancer: From basic findings towards therapeutic targeting. World J Gastroenterol 20 : 1681-1693, 2014

18. Singh JK, Farnie G, Bundred NJ, Simões BM, Shergill A, Landberg G, Howell SJ and Clarke RB: Targeting CXCR1/2 significantly reduces breast cancer stem cell activity and increases the efficacy of inhibiting HER2 via HER2-dependent and -independent mechanisms. Clin Cancer Res 19: 643-656, 2013

19. Kakinuma T and Hwang ST: Chemokines, chemokine receptors, and cancer metastasis. J Leukoc Biol 79: 639-651, 2006.

20. Müller A, Homey B, Soto H, Ge N, Catron D, Buchanan ME, McClanahan T, Murphy E, Yuan W, Wagner SN, et al: Involvement of chemokine receptors in breast cancer metastasis. Nature 410: 50-56, 2001.

21. Wang J, Zhang X, Thomas SM, Grandis JR, Wells A, Chen ZG and Ferris RL: Chemokine receptor 7 activates phosphoinositide-3 kinase-mediated invasive and prosurvival pathways in head and neck cancer cells independent of EGFR. Oncogene 24: $5897-5904,2005$.
22. Mburu YK, Egloff AM, Walker WH, Wang L, Seethala RR, van Waes $C$ and Ferris RL: Chemokine Receptor 7 (CCR7) gene expression is regulated by NF-B and Activator Protein 1 (AP1) in metastatic squamous cell carcinoma of head and neck (SCCHN). J Biol Chem 287: 3581-3590, 2012.

23. Yu H, Lee H, Herrmann A, Buettner R and Jove R: Revisiting STAT3 signaling in cancer: New and unexpected biological functions. Nat Rev Cancer 14: 736-746, 2014

24. Yamaoka K, Maeshima K, Kubo S and Tanaka Y: Regulation of inflammation through JAK3-Stat6 pathway in dendritic cells. Nihon Rinsho Meneki Gakkai Kaishi 35: 62-68, 2012 (In Japanese).

25. Bhavsar SK, Gu S, Bobbala D and Lang F: Janus kinase 3 is expressed in erythrocytes, phosphorylated upon energy depletion and involved in the regulation of suicidal erythrocyte death. Cell Physiol Biochem 27: 547-556, 2011.

26. Säemann MD, Zeyda M, Stulnig TM, Böhmig GA, Wekerle T, Hörl WH and Zlabinger GJ: Janus kinase-3 (JAK3) inhibition: A novel immunosuppressive option for allogeneic transplantation. Transpl Int 17: 481-489, 2004.

27. Uckun FM, Vassilev A, Dibirdik I and Tibbles H: Targeting JAK3 tyrosine kinase-linked signal transduction pathways with rationally-designed inhibitors. Anticancer Agents Med Chem 7: 612-623, 2007.

28. Valle-Mendiola A, Weiss-Steider B, Rocha-Zavaleta L and Soto-Cruz I: IL-2 enhances cervical cancer cells proliferation and JAK3/STAT5 phosphorylation at low doses, while at high doses IL-2 has opposite effects. Cancer Invest 32: 115-125, 2014.

29. Treliński J and Robak T: JAK inhibitors: Pharmacology and clinical activity in chronic myeloprolipherative neoplasms. Curr Med Chem 20: 1147-1161, 2013.

30. Ghoreschi K, Laurence A and O'Shea JJ: Janus kinases in immune cell signaling. Immunol Rev 228: 273-287, 2009.

31. Huang HL, Chiang CH, Hung WC and Hou MF: Targeting of TGF- $\beta$-activated protein kinase 1 inhibits chemokine (C-C motif) receptor 7 expression, tumor growth and metastasis in breast cancer. Oncotarget 6: 995-1007, 2015.

32. van den Bosch T, Koopmans AE, Vaarwater J, van den Berg M, de Klein A and Verdijk RM: Chemokine receptor CCR7 expression predicts poor outcome in uveal melanoma and relates to liver metastasis whereas expression of CXCR4 is not of clinical relevance. Invest Ophthalmol Vis Sci 54: 7354-7361, 2013.

33. Arigami T, Natsugoe S, Uenosono Y, Yanagita S, Arima H, Hirata M, Ishigami S and Aikou T: CCR7 and CXCR4 expression predicts lymph node status including micrometastasis in gastric cancer. Int J Oncol 35: 19-24, 2009.

34. Liu FY, Safdar J, Li ZN, Fang QG, Zhang X, Xu ZF and Sun CF: CCR7 regulates cell migration and invasion through JAK2/STAT3 in metastatic squamous cell carcinoma of the head and neck. Biomed Res Int 2014: 415375, 2014.

35. Liu FY, Zhao ZJ, Li P, Ding X, Guo N, Yang LL, Zong ZH and Sun CF: NF- $\kappa$ B participates in chemokine receptor 7-mediated cell survival in metastatic squamous cell carcinoma of the head and neck. Oncol Rep 25: 383-391, 2011.

36. Martin SK, Kamelgarn M and Kyprianou N: Cytoskeleton targeting value in prostate cancer treatment. Am J Clin Exp Urol 2: 15-26, 2014

37. Mashino K, Sadanaga N, Yamaguchi H, Tanaka F, Ohta M, Shibuta $\mathrm{K}$, Inoue $\mathrm{H}$ and Mori $\mathrm{M}$ : Expression of chemokine receptor CCR7 is associated with lymph node metastasis of gastric carcinoma. Cancer Res 62: 2937-2941, 2002.

38. Baggiolini M: Chemokines and leukocyte traffic. Nature 392 : $565-568,1998$ 